\title{
Numerical Investigation on the Effects of Tensioning on the Dynamic Performance of a Pantograph
}

\author{
lucky Adoh ${ }^{1}$, Lovejoy Mutswatiwa ${ }^{2}$, and Celestin Nkundineza ${ }^{2}$ \\ ${ }^{1}$ Addis Ababa University \\ ${ }^{2}$ Affiliation not available
}

November 26, 2020

\begin{abstract}
The aim of this analysis was to model the pantograph - catenary system at static equilibrium and provide analytical solutions by computing the natural frequencies of the system, mode functions, equivalent stiffness of the catenary system and the deflections of the catenary wire as a function of position, time and tensioning force. Furthermore, dynamic analysis was conducted analytically and the results of the dynamic performance were obtained. It was shown that the dynamic response of the catenary system is dependent on the design parameters in which tensioning force is included. It was also shown that low tensioning forces result in high risk of contact loss and increased wave propagation in the catenary wire while high tensioning forces result in increased static stresses in the catenary system. The results in this article can be used to select optimum tensioning forces and design parameters for desired pantograph-catenary dynamic performance.
\end{abstract}

\section{Hosted file}

new_manuscript.pdf available at https://authorea.com/users/378991/articles/495366-numericalinvestigation-on-the-effects-of-tensioning-on-the-dynamic-performance-of-a-pantograph 